\title{
As Empreitadas de Obras Públicas no Direito Brasileiro
}

\author{
CaIo Tácito \\ Professor de Direito Administrativo na Fa- \\ culdade de Direito da Universidade do Dis- \\ trito Federal.
}

\begin{abstract}
(Relatório sôbre o tema constante da ordem do dia do $X$ Congresso Internacional de Ciências Administrativas)
\end{abstract}

regime jurídico da empreitada de obras públicas, no Brasil, deve ter em vista, inicialmente, a discriminação da competência legislativa, fixada na Constituição, em decorrência dos princípios federativos.

Embora inscrito, entre os assuntos afetos à União, o de legislar sôbre direito civil e as normas gerais do direito financeiro (art. $5 .^{\circ}, \mathrm{n} .^{\circ} \mathrm{XV}$, alíneas $a$ e $b$ ), o sistema de execução dos serviços públicos obedece, ainda, à legislação dos Estados e Municípios, de acôrdo com os poderes reservados a essas pessoas jurídicas de direito público interno (Constituição, art. 18 e 28).

Lembra RuI CrRne Lima (Princípios de Direito Administrativo Brasileiro, $2 .^{a}$ edição, p. 181), que já o art. $10, \S 8 .^{\circ}$, do Ato Adicional (1834), atribuía competência às Províncias, sob o Império para "legislar sôbre obras públicas" que não pertencessem à administração central. Proclamada a República, conservaram os Estados - membros a antiga prerrogativa provincial, legislando sôbre a matéria em causa.

O estudo completo do tema conduziria, assim, ao exame comparativo não sòmente das vinte Constituições estaduais, como dos numerosos atos legislativos dos Estados e Municípios, relacionados com os contratos administrativos e o regime financeiro da despesa pública.

Não parece, no entanto, que a tentativa de súmula dos princípios gerais da empreitada de obras públicas, no direito nacional, reclame a indicação minuciosa das normas federais, estaduais e municipais.

Poder-se-á adotar como paradigma, sem margem apreciável de êrro, a lei federal que exprime as tendências dominantes do direito administrativo brasileiro, reproduzidas, em sua essência, nos demais planos da organização político-administrativa. 
As respostas ao questionário serão, portanto, dadas com apoio nos preceitos legais da União, acessòriamente complementados, quando aconselhável, pela remissão ao direito local.

\section{II}

A empreitada de obra pública é um contrato administrativo, em virtude de seu objeto, uma vez que se destina a atender à execução de um serviço público, ou a um fim de interêsse geral. pública:

Alfredo de Almeida PaIVA assinala, como elementos essenciais à obra

a) a natureza da Obra a ser feita ou a construir-se; dem;

b) que seja custeada, ou executada, pelo poder público, ou a sua or-

c) que se destine a atender ao funcionamento de um serviço público, ou tenha em vista um interêsse geral ou público. (Aspecto do contrato de empreitada, 1955, p. 150).

No mesmo sentido, com pequenas variações, o ponto de vista de Temistocles Cavalcanti (Tratado de Direito Administrativo, vol. II, p. 375), J. Guimarães Menegale (Direito Administrativo e Ciência da Administração, 2. ${ }^{a}$ edição, vol. II, p. 207), J. MATtos DE VAsconcellos (Direito Adiministrativo, vol. II, p. 114).

Esse contrato administrativo rege-se, ao mesmo tempo, por normas de direito privado e de direito público, segundo a regra geral do art. 766 , do Regulamento Geral de Contabilidade Pública, assim redigido:

"Os contratos administrativos regulam-se pelos mesmos princit pios gerais que regem os contratos de direito comum, no que concerne ao acôrdo de vontades e ao objeto, observadas, porém, quanto à sua estipulação, aprovação e execução as normas previstas no presente capítulo."

A empreitada, como contrato de direito privado, está disciplinada nos arts. 1.237 a 1.247 do Código Civil. A empreitada de obras públicas subordina-se, ainda, a normas especiais que podem ser sintetizadas nos seguintes aspectos básicos:

a) obrigatoriedade de concorrência pública, ou administrativa, salvo casos especiais;

b) celebração por autoridade competente para o empenho da despesa;

c) caução real em dinheiro, títulos públicos ou, excepcionalmente, mediante hipoteca de bens imóveis;

d) estipulação na presença de funcionário público competente, observadas as cláusulas esşenciais exigidas em lei;

e) aprovação pelo Ministro de Estado ou dirigente de órgão dotado de personalidade jurídica própria; 
f) publicação no órgão oficial;

g) registro pelo Tribunal de Contas;

h) pronunciamento do Congresso Nacional, no caso de recusa do registro pelo Tribunal de Contas.

Os contratos de empreitada de obra pública são, ainda, regulados pelas normas permanentes estabelecidas nos "Cadernos de Obrigações", de que é exemplo, no Distrito Federal, o Decreto Municipal n. ${ }^{\circ} 12.172$, de 31 de julho de 1953.

Entre as formas de execução que se aproximam da empreitada de obra pública devem ser indicadas a administração contratada, a tarefa e o ajuste. $\mathrm{Na}$ primeira, quem se encarrega da execução da obra concorre apenas com o seu trabalho, cabendo à administração os encargos da mão de obra e dos materiais de construção. A segunda consiste na execução da obra, a título precário, por meio de tarefeiros escolhidos a critério da administração. Existente, no Brasil, desde o Decreto número 2.922, de 10 de maio de 1862, entrou em declínio, até ser restaurada, em normas permanentes de lei orçamentárias, a partir de 1924. A sua adoção é feita em obras de valor limitado e de natureza tècnicamente simples. A terceira é a modalidade de atribuição sumária de tarefas, em obras de reduzido valor e a título precário.

Além da fiscalização administrativa, os contratos de obras públicas ficam sujeitos, como as demais formas de atividades administrativas, ao contrôle jurisdicional, exercido por intermédio do Poder Judiciário que, no regime brasileiro, obedece ao sistema da unidade de jurisdiç̧ão.

O contrôle de legalidade é fe.to, portanto, em duplo grau :

$\left.1 .^{\circ}\right)$ durante a formação do contrato, pelo registro obrigatório no Tribunal de Contas, visto que, segundo o artigo $77, \S 11^{\circ}$, da Constituição Federal, "os contratos que, por qualquer modo, interessarem à receita ou à despesa, só se reputarão perfeitos depois de registrados pelo Tribunal de Contas";

$2 .^{\circ}$ ) após a conclusão do contrato mediante decisão jurisdicional, de acôrdo com a competência específica do Poder Judiciário para apreciar "qualquer lesão de direito individual" (Constituição, art. 141, § 4..$^{\circ}$.

Feitas essas observações preliminares, passo a esclarecer os ítens constantes do questionário proposto pelo Instituto Internacional de Ciências Administrativas.

\section{III}

$1^{\circ}$ ) Em princípio, os contratos administrativos que interessem à receita ou à despesa pública devem ser precedidos de concorrência pública ou administrativa (art. 765 do Regulamento Geral de Contabilidade Pública). Em casos especiais, a lei dispensa a exigência, quando se trata de obras urgentes, de valor diminuto, ou quando não acudirem proponentes à concorrência (art. 51 do Código de Contabilidade Pública).

$2 .^{\circ}, 3 .^{\circ}, 4 .^{\circ}$ e $5^{\circ}$ ) A obrigação de concorrência pública ou administrativa é estabelecida segundo limites do valor financeiro do contrato, determinados em lei, ou atos normativos acessórios. 
A concorrência pública, aberta mediante edital público, divulgado no órgão oficial, é acessível a todos os que satisfizerem as exigências técnicas e financeiras, inclusive quanto à idoneidade e aptidão dos concorrentes. No edital de abertura da concorrência constará, além da indicação do serviço, o critério de julgamento, valor da caução, data e local da realização do ato e prazo máximo de execução do contrato.

A concorrência administrativa é feita mediante coleta de propostas entre empreiteiros prèviamente inscritos na repartição competente, observadas as demais condições inerentes às concorrências públicas. E, em suma, uma concorrência restrita aos candidatos escolhidos pela administração.

$\left.6^{\circ}{ }^{\circ}\right)$ Não há restrições aos participantes às concorrências públicas, senão em virtude das condições de idoneidade técnica ou financeira, estabelecidas no edital ou em normas permanentes. Segundo a natureza do serviço, poderão ser exigidas garantias especiais de defesa do interêsse da administração.

7. ${ }^{\circ}$ ) A outorga da empreitada é regulada, nos Estados e Municípios, pela legislação local e, nos organismos descentralizados (autarquias, sociedades de economia mista, emprêsas incorporadas ao patrimônio nacional, etc.), segundo o seu regime jurídico peculiar.

8..$^{\circ}$ As concorrências públicas são precedidas de editais divulgados no órgão oficial e na imprensa. O julgamento das propostas é, usualmente, feito após a abertura pública das propostas, com a assistência dos interessados. Também são públicas as sessões do Tribunal de Contas, por ocasião do registro dos contratos, cujo teor é obrigatòriamente publicado no órgão oficial.

9. ${ }^{\circ}$ ) O julgamento da concorrência é ato discricionário da administração que poderá deixar de escolher qualquer dos proponentes, segundo a conveniência do serviço. $\mathrm{Na}$ escolha definitiva do empreiteiro está, porém, a autoridade administrativa vinculada aos princípios legais e às normas específicas estabelecidas nas instruções de serviço e no edital da concorrência. Dispõe, a respeito, o art. $51, \S 10^{\circ}$, do Código de Contabilidade Pública da União:

"Verificada, em primeiro lugar, a idoneidade dos concorrentes, será escolhida, salvo outras razões de preferência antecipadamente assinaladas no edital, a proposta mais barata, que não poderá exceder de $10 \%$ os preços correntes da praça."

A proposta do concorrente deve observar a forma de execução do serviço constante do edital. A aceitação de ouțra solução técnica sòmente será possível, mediante anulação da concorrência aberta, instituindo-se nova concorrência nos moldes que forem admitidos pela administração.

10. $\left.{ }^{\circ}\right)$ O Código de Contabilidade Pública da União e o respectivo Regulamento Geral foram baixados em 1922, tendo sofrido alterações posteriores. Estando obsoletas muitas de suas disposições, o Poder Executivo tem o propósito de apresentar projeto de lei, no sentido de ser elaborado, pelo Congresso, novo ato legislativo. Há, a respeito, anteprojeto recentemente organizado por uma comissão de técnicos.

$\left.11 .^{\circ}\right)$ Sim. Perante cs juízes e tribunais judiciários. As concorrências, como as demais fases constitutivas do contrato poderão ser anuladas no todo, 
ou em parte. A indenização eventual por ato ilícito da administração regularse-á pelos princípios da responsabilidade civil do Estado. Nenhuma rescisão de contrato, que importe indenização, poderá ser feita, nos serviços federais, sem prévia autorização do Congresso Nacional (art. 798 do Regulamento Geral de Contabilidade Pública).

12..$^{\circ}$ A empreitada de obra pública é contrato intuitu personae não podendo ser transferido, no todo ou emi parte, sem prévia arıência da admınistração.

$\left.13 .^{\circ}\right)$ As condições contratuais fixadas para a execução do serviço sòmente poderão ser modificadas mediante têrmo aditivo e de comum acôrdo. E lícito, porém, ao Estado, mediante ato legislativo, estabelecer novas condições que afetem aos contratos existentes.

$14 .^{\circ}$ ) a) As conđições financeiras são estabelecidas no contrato, observadas as condições legais e os têrmos do edital da concorrência. Não há, em regra, salvo pacto especial, o financiamento dos trabalhos por parte da administração.

b) A administração tem o poder de fiscalização permanente da execução das obras e o de verificar a exatidão dela, no ato do recebimento. Se a obra executada não corresponder à encomenda poderá recusá-la, ou exigir abatimento de preço, tendo, ainda, a faculdade de declarar o empreiteiro inidôneo para transacionar com o Estado.

c) Em princípio, de acôrdo com o artigo 1.246 do Código Civil, "o arquiteto, ou construtor, que, por empreitada, se incumbir de executar uma obra segundo plano aceito por quem a encomenda, não terá direito a exigir acréscimo no preço, ainda que o dos salários, ou o do material, encareça, nem ainda que se altere ou aumente, em relação à planta, a obra ajustada, salvo se se aumentou, ou alterou, por instruções escritas do outro contratante e exibidas pelo empreiteiro."

A jurisprudência tem admitido, contudo, em casos excepcionais, reajustamento no preço da empreitada, aplicando a teoria da imprevisão, cuja incidência, nos contratos administrativos, também é aceita, quando intolerável e imprevisto o acréscimo no custo do serviço (ver, sôbre o assunto, meus trabalhos "Os contratos administrativos e a teoria da imprevisão", in "Arquivos do Ministério da Justiça", vol. 47, p. 5-s e "Teoria da Imprevisão". A cláusula rebus sic standibus nos contratos administrativos", in Revista Forense, vol. 98, p. 490).

Nos contratos de obras da Prefeitura do Distrito Federal figura cláusula obrigatória limitando a revisão de preços aos casos de elevação ou redução de tributos, ou de salários, na proporção mínima de $10 \%$ (Lei n. ${ }^{\circ} 806$, de 7 de dezembro de 1954 , artigo $4 .^{\circ}$ ).

d) Não há, a respeito, normas legais permanentes. Os cadernos de encargos, ou as cláusulas contratuais regularão a matéria.

15..$^{\circ}$ A execução do contrato é fiscalizada pela administração que poderá aplicar multas aos empreiteiros faltosos, ou mesmo, rescindir o contrato. O Poder Judiciário exerce o contrôle de legalidade do contrato e da ação administrativa dêle decorrente. 
16. ${ }^{\circ}$ Não há regras especiais a respeito. Os atos administrativos relacionados com o contrato ficam sujeitos aos recursos próprios, segundo a hierarquia.

17. ${ }^{a}$ ) $\mathrm{Na}$ forma do direito comum, poderão as controvérsias sôbre a execução do contrato ficar sujeitas a juízo arbitral, mediante compromisso judicial ou extrajudicial. O juízo arbitral, regulado nos artigos 1.037 a 1.048 do Código Civil, embora aplicável, em tese, aos contratos administrativos, não é, de fato, adotado para êsse fim.

\section{CONCLUSÃO}

A luz do direito e da prática administrativa no Brasil, a conclusão mais adequada é a prevista na terceira fórmula (alínea c) do questionário. 